\title{
Impact of User Ratings on Mobile Apps Due Fault and Change Proneness in API
}

\author{
Rohith Peddigari1)
}

\begin{abstract}
An Application Programming Interface (API) is a set of protocols used for building a software. The mobile application (apps) market is growing very fast with the number of mobile apps increasing at a rapid rate in the recent few years. It is natural that users' tend to use the apps that are less prone to bugs, crashes etc. which demands the developers to create a reliable app in order to sustain in the competent mobile application market. In this paper we study about how the fault-proneness and change-proneness of APIs used have a direct impact on the users' ratings of the mobile apps. It is no surprise that the apps whose API's are less prone to faults and changes receive higher ratings than the ones in which the frequency of the faults and changes are relatively higher.
\end{abstract}

Keywords: mobile, apps, API, software, fault-proneness..

\section{Introduction}

A portable application, short for versatile application or just application, is an application programming intended to keep running on perspicacious telephones, tablet PCs and other portable devices[1]. An Application bodes well or is wanted if the objective is to have an intuitive engagement with clients, or to give an application that requires to work more likened to a PC program than a site[2-3]. Applications are accessible by means of conveyance stages on cement application stores[4]. There are free and additionally paid applications. There are couple of applications which at first are accessible for nothing, yet later a base expense is required to relish premium advantages. "The iphones' intense programming, progressive client interface, and capable improvement stage had driven an overnight blast of applications "Most broadly utilized cell phones for the portable applications are iPhone, BlackBerry, Android telephone or Windows Telephone[5]. For applications with a value, for the most part a rate, 20-30\%, goes to the dispersion supplier and the rest goes to the maker of the application. As indicated by portable

Received(March 24, 2015), Review Result(1st: April 9, 2015, 2nd: May 8, 2015), Accepted(May 10, 2015)

${ }^{1}$ (Corresponding Author) Department of Computer Science and Engineering, KL University email: peddigarirohith@gmail.com 
details, the quantity of applications introduced by the normal perspicacious telephone client (Worldwide) is 26. So this number limpidly demonstrates that applications are the practical through which shoppers need to expend content on cell telephones[6].

Initially versatile applications were offered for instructive and efficiency purposes that included email, timetable, contacts, adding machine and climate data. With the fast amplification in the innovation and clients' prospects the engineer executes ventured into different classes, for example, versatile amusements, GPS, managing an account, ticket buys, online networking, video talks, production line mechanization, area based administrations, wellness applications and as of late portable restorative applications[7].

An application can concentrate substance and data from the web in a comparative manner to a site, yet it can likewise download the substance with the goal that it can be used later without Web association which is an extraordinary favorable position. So applications that needn't bother with web association can be utilized "anyplace and all around" i.e. application can be utilized disconnected from the net. Few detriments of the ubiquity of portable applications has propagated to raise, as their utilization has turned out to be more pervasive crosswise over cellular telephone clients. This is pellucidly clear from thenumbers given by i.e. Aggregate anticipated Portable application downloads in 2013 is 102 billion and the Aggregate anticipated versatile application income in 2013 \$26 billion. There are a few sites and a couple articles that have caught the insights of portable applications regarding the quantity of designers developing every year, the quantity of applications expanding each year, incomes produced from applications, the quantity of applications that are showing up on diverse stages and most prominently utilized applications on distinctive stages. Very few sites/articles verbalize about the quantity of applications being erased, the quantity of clients erasing applications, the quantity of good applications versus rotten ones, considers that entice clients to erase applications, the components that cause terrible applications. There is restricted writing on how great applications can be made extraordinary applications and how terrible applications can be revised to wind up great and incredible.

\section{Literature Survey}

As indicated by the "World Portable Applications Market - Propelled Advances, there were around 6.4 billion (free, paid, and promotion bolstered) applications, that were downloaded in 2009 alone which created incomes of $\$ 4.5$ billion around the same time. Apple governed this 
business sector with 2.5 billion downloads from its store in 2009. Later, other business sector players like Android, Google, and Nokia have begun making a commercial center for themselves in the versatile applications field with the developing advanced cell market.

The statistical surveying directed by IDC predicts that the business sector for portable applications will keep on quickening as the quantity of downloaded applications is relied upon to increment from 10.9 billion worldwide in 2010 to 76.9 billion in 2014. Comparative development will be seen in the incomes of portable apps (worldwide), surpassing \$35 billion in 2014.

The above measurements are in congruity with the data gathered from applications running on "Whirlwind Examination" stage from 2012 to 2013. The chart in graph (2.1) underneath unmistakably assigns that the application begins (as these new applications' appearances are being anticipated) have approximately multiplied. In this way, there has been an enduring development in the quantity of applications as augured by diverse economic scientists with the increasing prominence of versatile applications, there has been a weighty amplification in the quantity of portable application engineers also. From the information recorded by whirlwind investigation, the quantity of portable application designers with a group of people more than one million month to month dynamic clients, has gone from 400 to 875 in the same span, i.e. from 2012 to 2013 as outwardly saw in graph (2.1). The quantity of versatile application engineers with a group of people more than 20 million dynamic month to month clients has furthermore encountered an incrementation as saw in graph (2.2). This lift in the quantity of application designers moreover recommends that there are a few early applications being coordinated into the as of now subsisting ones.

As presented above the greater part of the measurements just speak to the incrementation in the quantity of applications or the quantity of clients and number of designers consistently, yet very little exertion has been made to record the information on the quantity of clients that are erasing a specific application, the normal existence of an application, i.e. to what extent does a normal client holds a specific application on his/her advanced cell; and how frequently do the clients switch to different applications. Research by Mobilewalla uncovered that clients in the end cancel 90 percent of all downloaded applications. One incorrect move that vexes or disappoints clients - and chances are the application will be erased. The following few areas in this paper attempt to verbalize about the variables bringing on awful applications, which would give bits of knowledge on why clients provoked to cancel the mobile application.

As per the top negative surveys and measurements, "44\% verbally express they would erase a versatile application quickly if application did not execute not surprisingly". The numbers 
obviously bring up that there are great applications, and grievous applications in the application market. Application clients uninstall the application, as well as withal give negative audits on the application when clients don't savor the application.
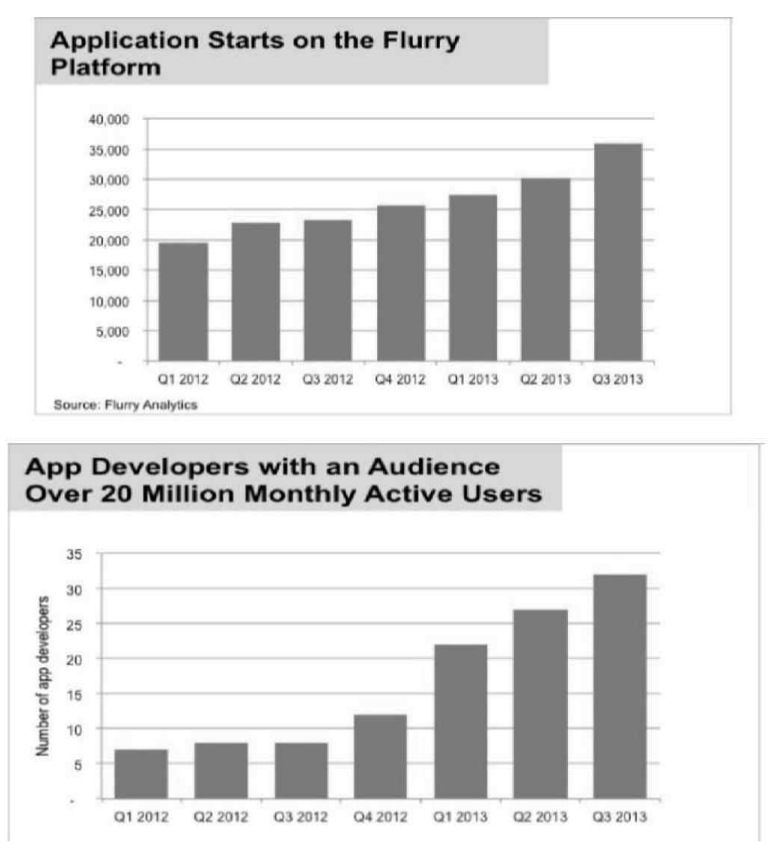

[Fig. 1] Increase in the number of app developers from 2012

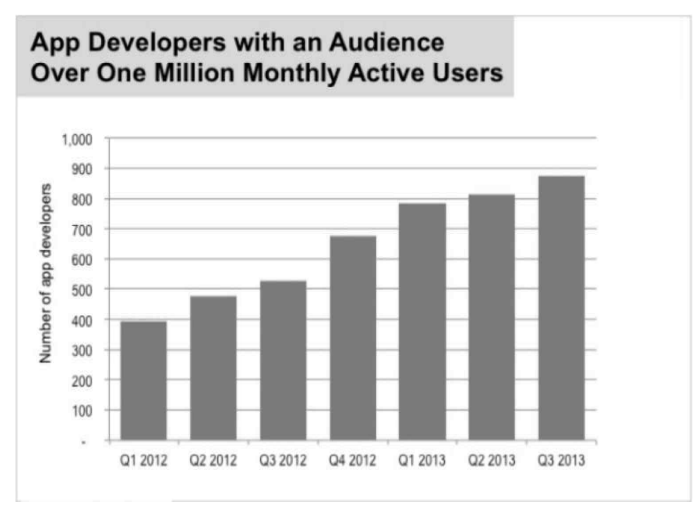

[Fig. 2] Developers versus Users

With online networking and informal exchange being so prominent negative surveys spread quickly, which thoroughly influences the notoriety of designers and represents a danger to their future discharges. Consequently it is exceptionally basic for the engineers to comprehend the measure for good applications versus awful applications and grow as needs be variables 
contribute towards expanding Volume - putting away exchange information, live gushing information and information gathered from sensors and so on.
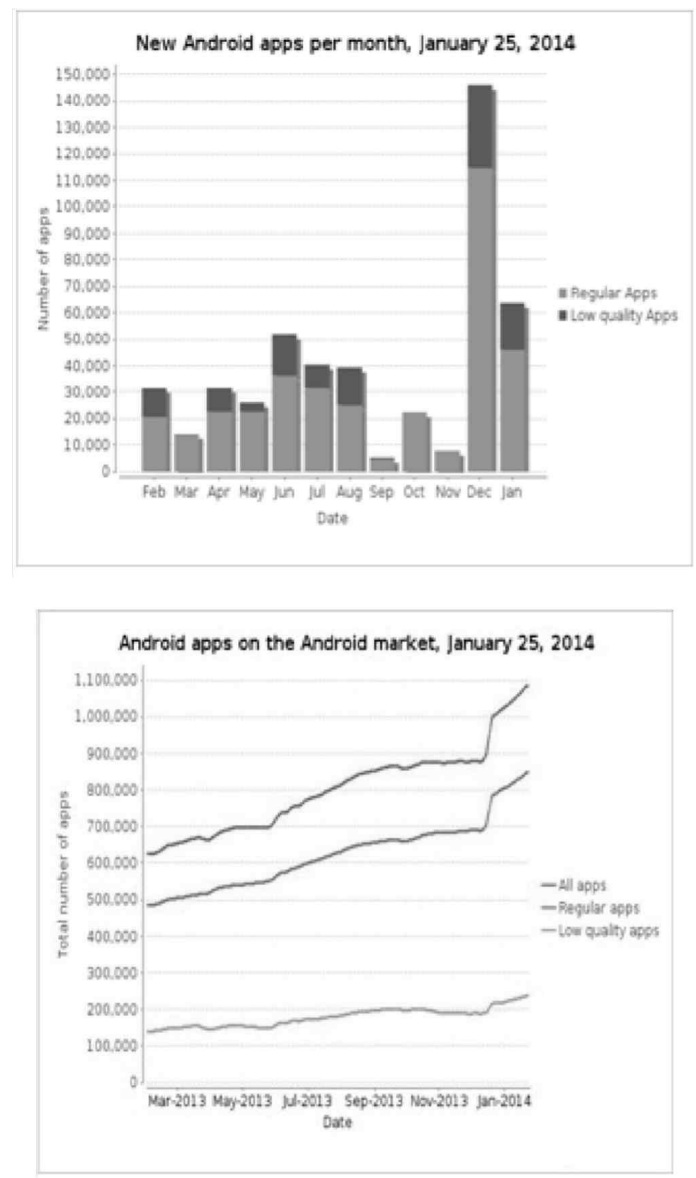

[Fig. 3] High quality vs Low quality apps

Downloading issues, is not steady crosswise over different stages, has similarity issues, devours part of battery force, has a moderate replication capacity, has high commercial recurrence, is not fittingly valued, and has no tries made to calibrate issues/concerns raised by the clients. Applications must be overhauled routinely to keep clients engaged and locked in. In the event that an application is made and has never been taken a gander at again, then the application could be considered an awful application.

In view of the late data it is clearly apparent that with the ascent in the quantity of applications, the quantity of wretched/low quality applications are furthermore ascending as portrayed in graph (2.3). The rate of low quality applications (22\%) as said on is an 
exceptionally noteworthy number and demonstrates that there is a prompt need to focus on the nature of applications. With a few applications on board and with a huge number of choices, the purchasers are convinced to purchase very cleaned applications, thus the business sector is no more positive to novice applications.

Frequency

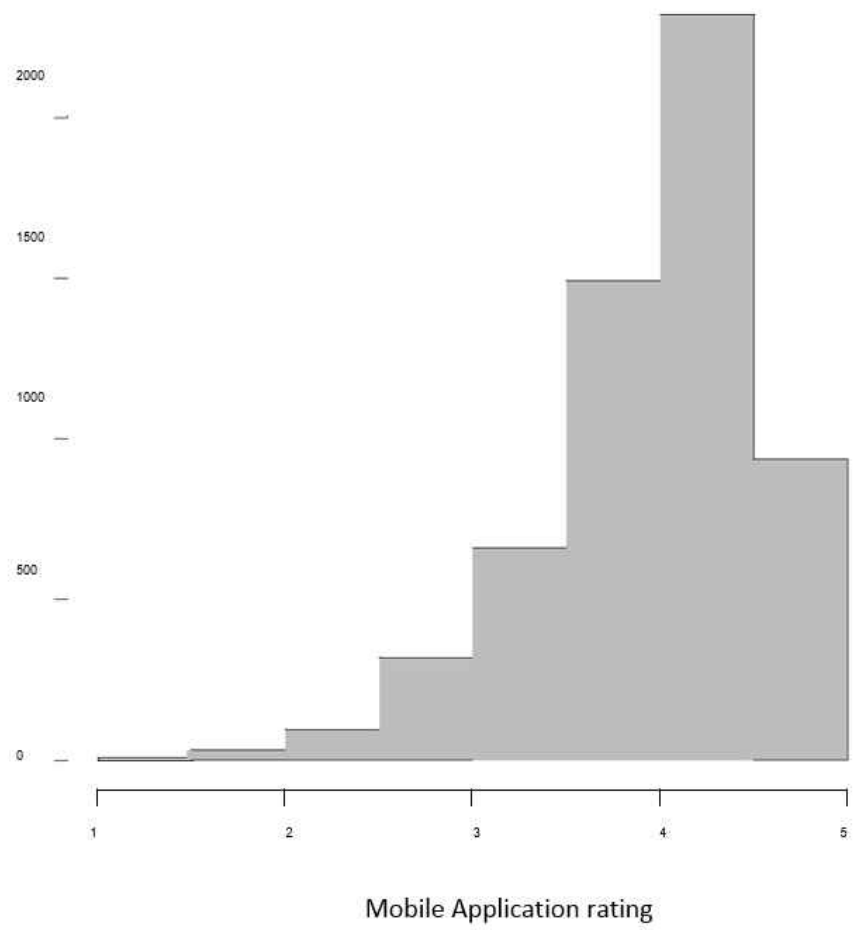

[Fig. 4] User ratings on mobile apps

"Terrible" alludes - not adjusting to models. An application can be thought to be unfortunate in the event that it has a poor configuration/UI(naïve developers), has part of mess, has poor route, does not meet the client prerequisites, does not address a particular issue, has security issues, comes up short at certain vital times, has downloading issues, is not predictable crosswise over different stages, has similarity issues, devours parcel of battery force, has a moderate replication capacity, has high notice recurrence, is not suitably estimated, and has no tries made to adjust issues/concerns raised by the clients. Applications must be overhauled consistently to keep clients engaged and locked in. On the off chance that an application is made and has never been taken a gander at again, then the application could be considered an 
awful application

The graph (2.4) reports the appropriation of the normal appraisals doled out by clients to these applications. When all is said in done, the client appraisals are high: displaying a normal rating more prominent than 4 stars. By the by, because of very expansive corpus of applications considered in our study, we additionally have some applications with a normal rating lower than 3 stars. In this way, we can confirm a conceivable relationship in the middle of issue and change-inclination of utilized APIs and applications normal client rating. One may be enticed to trust that such applications got high scores as a result of being free, i.e., the client is less baffled when an application is problematic or futile, in light of the fact that he/she didn't burn through cash for it or, in actuality, a great and free usefulness is exceedingly compensated.

From the above graph we can analyze that most of the mobile apps are rated between 3.5 to 4.5 whereas very less number of mobile apps received a 1 rating and little number of mobile apps received low ratings between 2 to 3 rating.

\section{Theoritical Analysis}

\subsection{McCall's quality model}

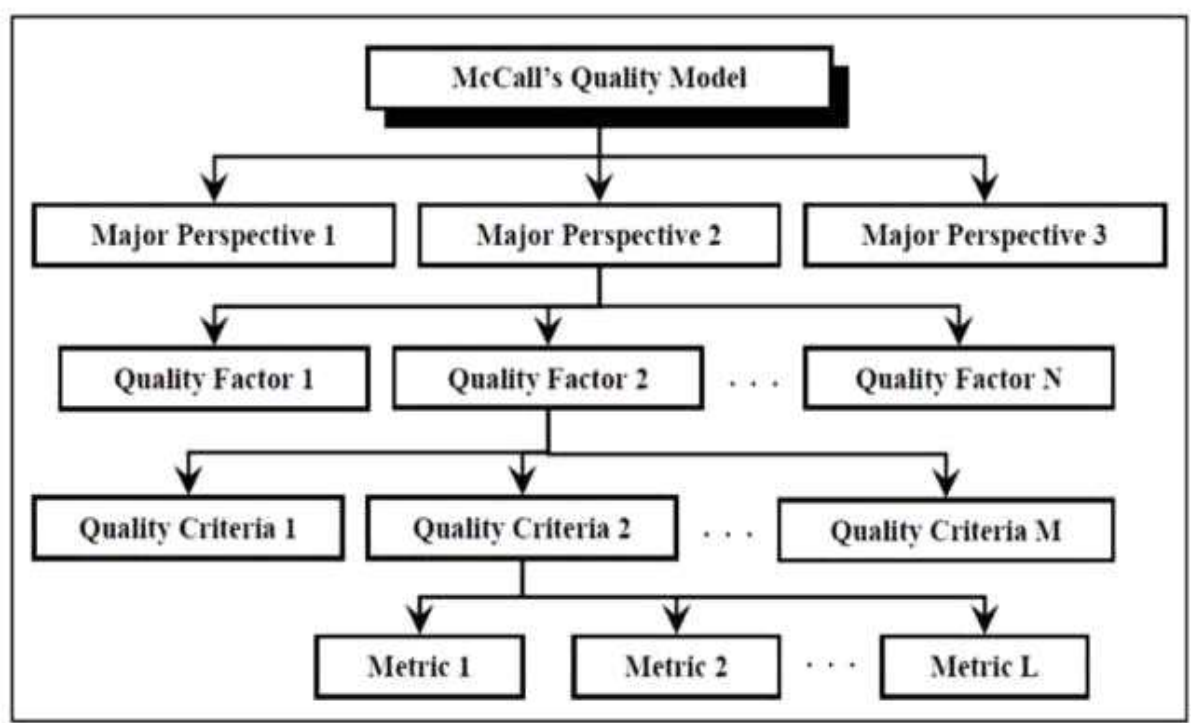

[Fig. 5] McCall's model structure 
This model was proposed by Jim McCall produced this model for the US Air Force and his major intention was to reduce the gap between users and developers.

McCall's model contains three main perspectives for characterizing the quality attributes of a software products they are :

1) Product revision

2) Product transition

3) Product operations

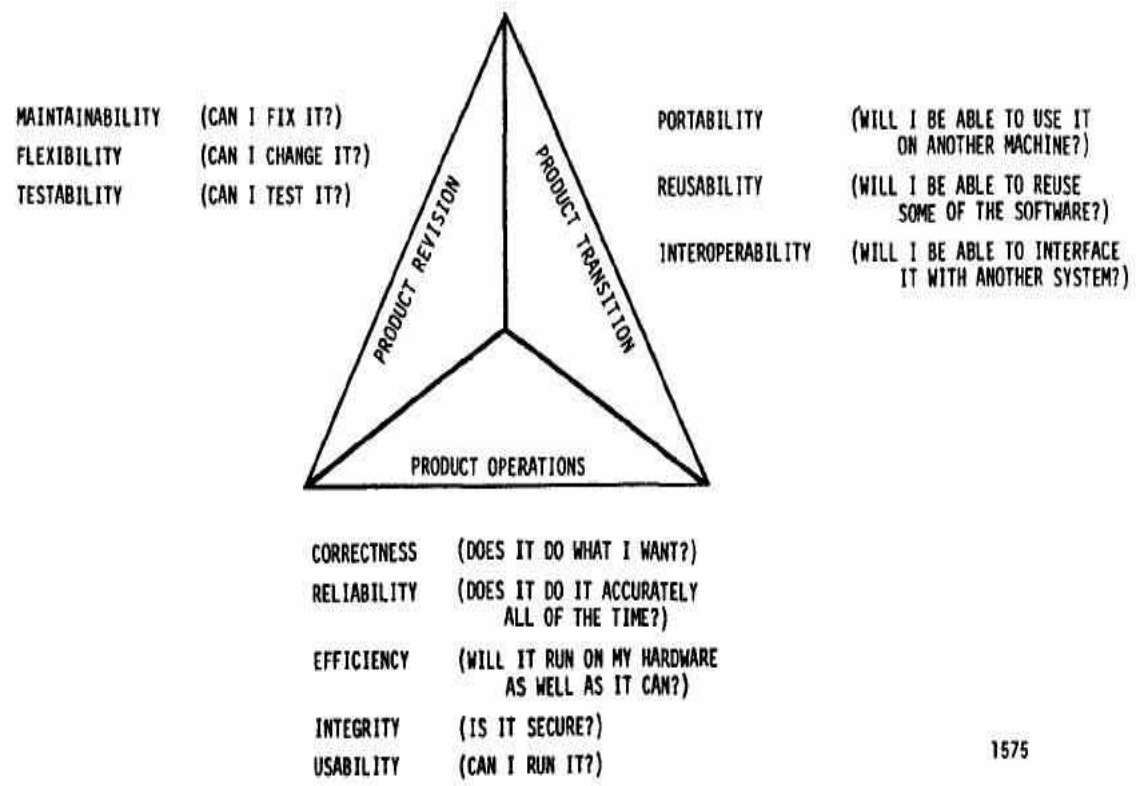

[Fig. 6] Software quality factors

\subsubsection{Product revision}

Product revision includes quality factors that influence the ability to change the software product, these factors are:

Maintainability: Ability to fix a defect.

Flexibility: Ability to make changes as per the requirements.

Testability: Ability to validate the software requirements.

\subsubsection{Product transition}


Product transition includes quality factors that influence the ability to adapt the software to new environments:

Portability: Ability to switch the software from one environment to another.

Reusability: Ease of use of the software components.

Interoperability: Ease to which different software components work together.

\subsubsection{Product operations}

Product operations includes quality factors that influence the extent to which the software fulfils its specification:-

Correctness: The accuracy of the system.

Reliability: The extent to which the system gives accurate results.

Efficiency: Resource usage.

Integrity: Protection from unauthorized access.

Usability: Ease of use.

\subsection{Boehm's quality model}

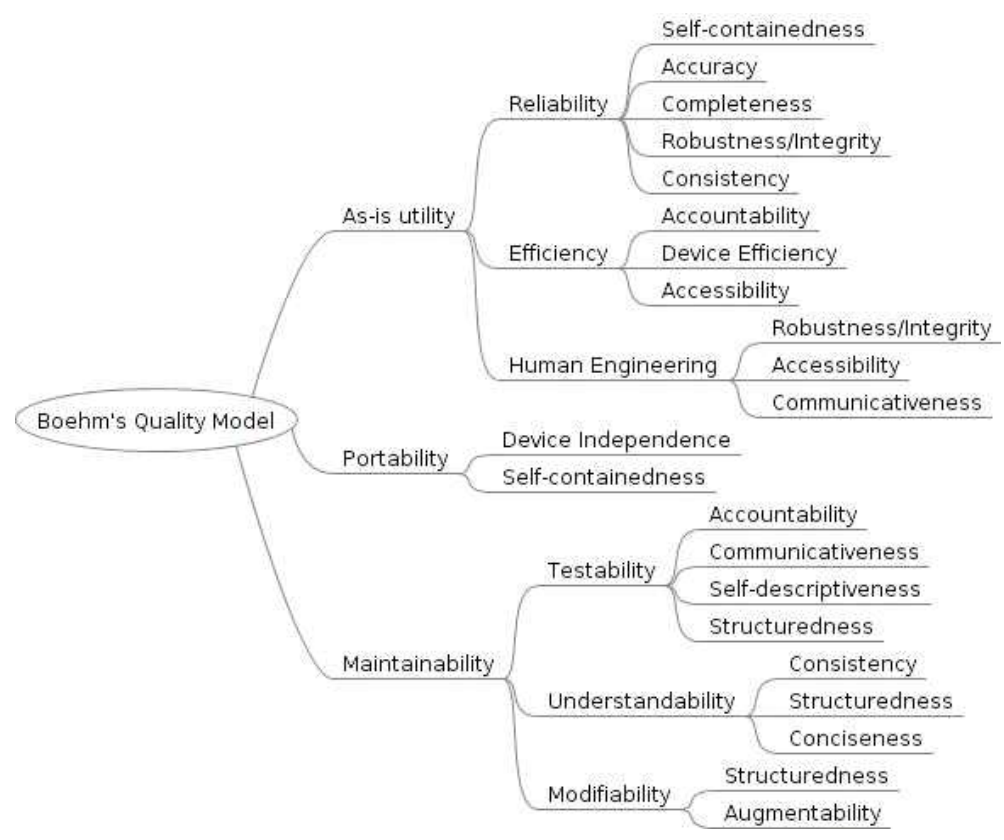

[Fig. 7] Bohem's model flowchart 
This model was proposed by Barry W. Boehm. The Boehm's model is also defined as a hierarchical model of software quality characteristics trying to define software quality as a set of attributes. There are three basic requirements of the Boehm's model they are:

- As-is utility: Extent to which the software can be used easily and efficiently.

- Maintainability: Ease of identifying changes to be done.

- Portability: Ease of changing software to a new environment.

These three primary represent the Boehm's hierarchical model. Boehm identified seven quality factors, namely:

Portability: The extent to which the software may work.

Reliability: The extent to which the software performs as required, i.e. the absence of defects.

Efficiency: Use of system resources.

Usability: Ease of use.

Testability: Checking whether the software meets the requirements.

Understandability: The extent to which the software is easily understandable.

Flexibility: The ease with which the software can be changed.

These quality elements are further separated into Primitive develops that can be measured, for instance Testability is separated into: openness, informativeness, structure and self-distinction. Similarly as with McCall's Quality Model, the expectation is to have the capacity to quantify the most reduced level of the model. Both of McCall and Boehm models take after a comparative structure, with a comparative reason. They both endeavor to breakdown the product antique into develops that can be measured. Some quality elements are rehashed, for instance: ease of use, conveyability, effectiveness and unwavering quality. The vicinity of pretty much elements is not, be that as it may, characteristic of a superior or more terrible model.

\subsection{Dromey's quality model}

Dromey's quality model is somewhat similar to the McCall's and the Boehm's quality model. It is proposed by R. Geoff Dromey. He proposed a product based quality model which recognizes that the evaluation of the quality factors in the software differs for each product and that the modelling process must be implemented in a more dynamic manner as the 
existing models are not wide enough to apply for different systems. Dromey focused on the relationship between the quality of the software and the sub-attributes of the software and established a relationship between software products and software quality attributes.

1) Various properties that influence quality of the software.

2) Other high level quality attributes of the software.

3) Establishing relationship between product properties and quality attributes.

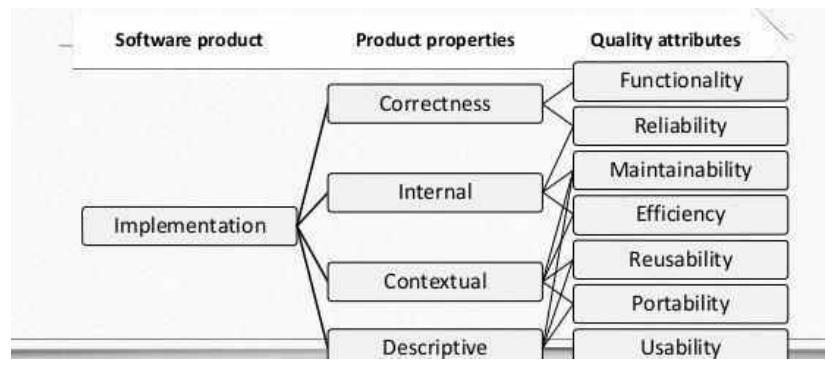

[Fig 8] Dromey model

Dromey's Quality Model is further structured around a 4 step process:

1) Selecting a set of high-level quality attributes for evaluating the software.

2) List the components present in the software.

3) Identify quality.

4) Effect of each property on the quality attributes

\subsection{FURPS quality model}

FURPS quality model is not such a popular model when compared with the other software models that are proposed. FURPS model was proposed by Robert Grady and was extended later. FURPS stands for:

Functionality: Includes the abilities of the software and the various security aspects of the software.

Usability: Includes the ease of use, consistency with the graphic user interface.

Reliability: Includes the frequent failures of the software, the ability of the software to 
produce accurate results and the predictability of the software.

Performance: Includes the factors such as speed at which the software runs, efficiency of the software, and the throughput of the software.

Supportability: Includes the compatibility nature of the software.

\section{Experimental Investigations}

\subsection{App disappointment - Role of the designer}

Designers ought to take enough care while constructing an application. Specifically, inducing an application for an association's image/item/administration requires supplemental consideration. Versatile App is one of the fundamental advertising executes for any item/benefit. It may assemble/annihilate the brand value and brand bond, as indicated by its execution. Furthermore, facilitate consideration is required when creating basic applications like managing an account application since it is exceptionally burdensome to persuade clients in regards to the security of such applications. Awkwardly heavy Advertising ought to be shunned on applications like managing an account on the grounds that, appearing of advertisements throughout an exchange power terrify the clients with respect to their own managing an account security.

Designers are the as a matter of first importance ones who are in charge of the disappointment of an application. There are different reasons which incorporate absence of aptitude as far as application advancement, negligible assets, least/no learning of client requests and desires, no information of target gathering of people, and absence of correspondence between designers of an application. Underneath said are some proposals that would help designers to hold off from making terrible applications.

\subsection{App disappointment Role of the User}

Clients/purchasers possess a critical part in the achievement/disappointment of an application. A Mobile App audit study was led by which had an example of more than 500 American versatile application clients, matured 18 years or more established. As indicated by the aftereffects of the review "96\% of the American versatile application clients say there are disappointments that would lead them to give an application an awful survey", accompanying: 


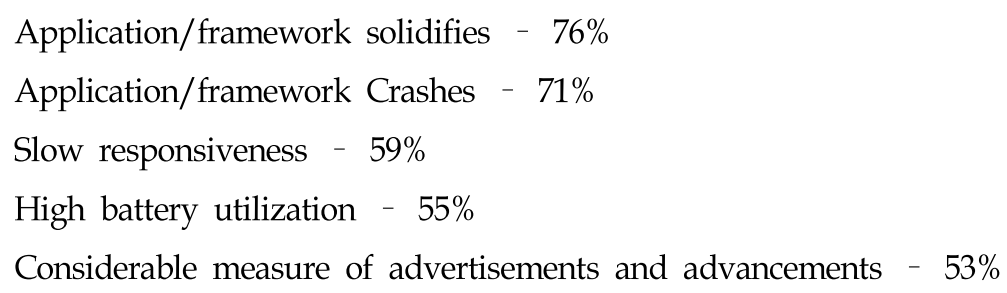

The overview likewise has recorded the measurements of the quantity of clients for whom execution matters the most. With no uncertainty, the number is $98 \%$, i.e. every application client considers execution as his/her primary need. At the point when the clients were addressed about the kind of applications, for which the execution mattered the most: $74 \%$ said saving money applications, trailed by maps (63\%), portable installments (55\%), versatile shopping $(49 \%)$, diversions $(44 \%)$ and online networking $(41 \%)$.

Fascinating measurements have additionally been recorded with respect to the outcomes of poor execution of applications; $44 \%$ of the clients would erase the application quickly, 38\% would erase the application in the event that it would solidify for more than 30 seconds, 32\% would utilize a negative verbal exchange to advise about the awful execution, $21 \%$ would post their negative remarks on online networking, (for example, facebook, twitter, and web journals), $18 \%$ of the specimen reacted by saying that their understanding time is just around 5 seconds, i.e. they would erase the application on the off chance that it solidified even only for 5 seconds and this number is relied upon to increment definitely later on. Despite the fact that the number is little; $27 \%$ of individuals said they would keep a paid application somewhat more despite its poor execution, yet the harm is as of now done which is not effortlessly repairable. The clients would not want to purchase any such applications later on from that specific designer/brand. A few recommendations for the clients that would profit enhance the execution of applications are given underneath

\subsection{Application Failure-Role of Technical subtle elements}

Most Mobile application engineers and merchants at times fall flat inefficaciously conveying the specialized subtle elements of the application to the end clients, the consequence of which is a generous harm to the success of an application. Top of the line amusements can be 
effectively played just on top of the line cell phones, in any case, because of the absence of specialized subtle elements, clients would download and try to play the diversion on non-compatible cell phone designs. Such inconsistency issues would bring about the telephone to either stop or crash or react step by step. This outcomes in woeful surveys from the clients and harm is done to the notoriety of the application.

\subsection{App disappointment Role of Marketing}

With such a variety of engineers building new applications every day, it is turning out to be to a great degree hard to obtain/pull in, hold and adapt clients and to create brand value and devotion. Engineers and applications are like brands who should be marketed. App promoting plays a basic part in the achievement/disappointment of a versatile application. Showcasing and social endeavors are required to keep customers drew in after the application is downloaded to their gadget.

Lacking promoting endeavors and advertising methodologies will prompt decrease consequently on ventures and subsequently will bring about disillusionments and dissatisfactions. $70 \%$ of engineers are baffled with the present condition of application advertising. The following are a portion of the components that cause promoting endeavors to fall flat and proposals are given in this effectual advertising.

Tight Budget: Budget is one of the real issues that designers are concerned. To reach bigger gatherings of people, designers need to work with some notice office suppliers to advance their applications. On the other hand, working with advertisement organizations requires a venture which is once in a while gigantic.

Lack of Trust in the commercial system suppliers: Most of the designer's today are baffled with the absence of clarity given by commercial system suppliers, and henceforth are thinking that it is hard to trust them. It is exceptionally costly to publicize an application through offices thus trust assumes a noteworthy part while making such ventures. Numerous designers are worried that the commercial system suppliers are not speaking the truth about their income claims with $71 \%$ of designers communicating the perspective that eCPM (successful Cost Per Thousand Impressions) was overstated, i.e. eCPM's were utilized to draw them in however these would frequently keep going for a brief period before coming up short. 


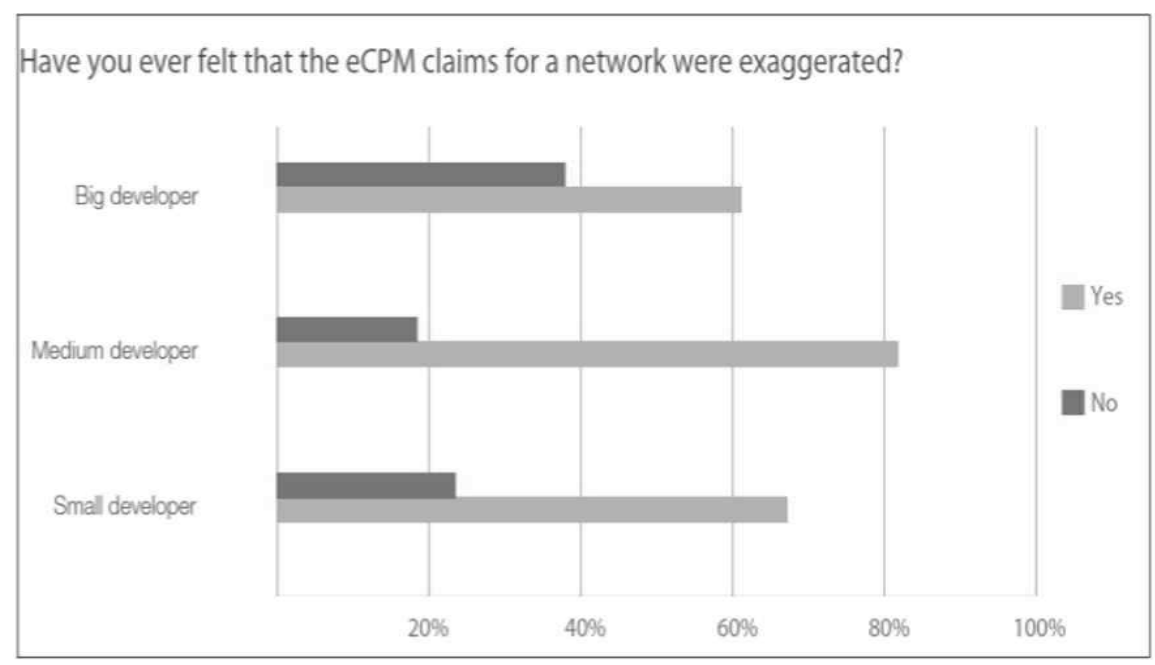

[Fig. 9] Difficulties faced by developers due to marketing

\section{Conclusion}

With the App Store is such an exceptional achievement, versatile applications have turned into a crucial part of the client's day by day life. To get success in the present versatile world, simply building up an application is not simply enough. Therefore, the objective of the designer is to keep a receptive outlook and grasp imaginative methods that can profit revise the life cycle (gathering prerequisites, plan, improvement, testing, and upkeep) of an application while upgrading client fulfillment. New advances are rising each day, and subsequently designers ought to dependably be all around notified about current patterns, necessities, and occasions in the portable innovation field. There will dependably be beginning parkways that will emerge later on for growing new and creative applications. With such new and promising open doors emerging each day for portable application designers, what's to come guarantees to be a luring trip.

\section{References}

[1] G. Bavota, The Impact of API Change- and Fault-Proneness on the User Ratings of Android Apps, IEEE Transactions on Software Engineering, (2015), Vol.41, No.4, pp.384-407.

[2] V. N. Inukollu, D. D. Keshamoni, T. Kang, and M. Inukollu, Factors Influencing Quality of Mobile Apps:Role of Mobile App Development Life Cycle, International journal of Software Engineering \& Applications (IJSEA), (2014), Vol.5, No.5, pp.15-34. 
[3] F. J. J. Mark, J. P. Anson, and F. J. Fabozzi, The Handbook of Traditional and Alternative Investment Vehicles: Investment Characteristics and Strategies, (2011), Wiley.

[4] http://www.developereconomics.com/reports/q3-2013/, August 25 (2014).

[5] http://www.visionmobile.com/product/developer-economics-2012/, October 20 (2014).

[6] https://www.consumerpsychologist.com/, October 20 (2014).

[7] G. Bavota, M. Linares-Vásquez and C. E. Bernal-Cárdenas, The Impact of API Change- and Fault-Proneness on the User Ratings of Android Apps, IEEE Transactions on Software Engineering, (2014), Vol. 41, No.4, pp.384-407.

[8] I. A. Herrera and R. Woltjer, Comparing a multi linear (STEP) and systemic (FRAM) method for accident analysis, Reliability Engineering and System Safety, (2010), Vol.95, pp.1269-1275. 